\title{
A Afetividade na Educação Online: Percursos e Possibilidades
}

\section{Affectivity in Online Education: Paths and Possibilities}

\section{Adriana Baptista}

Universidade do Estado do Rio de Janeiro (UERJ/Cederj) - Rio de Janeiro RJ - Brasil.

\section{Vivian Martins}

Instituto Federal de Educação, Ciência e Tecnologia do Rio de Janeiro (IFRJ). Rio de Janeiro - RJ - Brasil. vivian.martinst@gmail.com

\section{Resumo}

O artigo aprofunda conhecimentos sobre a afetividade na educação online, considerando o afeto, a interatividade, a colaboração, a coautoria e a aprendizagem significativa como fatores preponderantes para o sucesso na modalidade. O método é a pesquisa-formação na cibercultura, que não separa a docência do ato de pesquisar. Não há centralidade no docente, nos conteúdos, nas tecnologias nem nos praticantes ciberculturais; a centralidade está na rede que se forma entre todas essas interlocuções. O contexto foi o curso de extensão Formação de Docentes para a Educação Online ministrado no Instituto Federal do Rio de Janeiro, campus Belford Roxo, em que ambiências formativas e dispositivos de pesquisa na educação online foram acionados para compreender as questões norteadoras do estudo. Como achado da pesquisa, tem-se a noção subsunçora "Atividades síncronas: pertencimento e afetividade", emergente das narrativas dos praticantes, do diálogo bibliográfico, da imersão no cotidiano da pesquisa e do dispositivo "síncrono ou assíncrono? Eis a questão...", acionado utilizando um fórum de discussão para que mais dados sobre a afetividade pudessem emergir. O achado da pesquisa proporciona saberes para melhores práticas como docentes online, assunto de extrema importância para a Educação em contexto de cibercultura.

Palavras-chave: Afetividade, Educação Online, Pesquisa-formação, Cibercultura. 


\section{Affectivity in Online Education: Paths and Possibilities}

\section{Abstract}

The article aims to deepen knowledge about affectivity in online education, considering affection, interactivity, collaboration, co-authorship and meaningful learning as preponderant factors for success in the modality. The method used is the research-training in cyberculture, which does not separate teaching from the act of researching. There is no centrality in the teacher's role, in the contents, in the technologies nor in the cybercultural practitioners, the centrality is in the network that is formed among all these interlocutions. The context was the Extension Course "Teacher Education for Online Education", taught at the Federal Institute of Rio de Janeiro, Campus Belford Roxo, where training environments and research devices in online education were used to understand the guiding questions of the study. As a result of the research, the previous notion "Synchronous activities: belonging and affectivity" emerges from the narratives of the practitioners, from the bibliographic dialogue, from the immersion in the daily routine of research and from the "synchronous or asynchronous" device. Here's the question ..." triggered using a discussion forum so that more data on affectivity could emerge. This research provides knowledge for best practices as online teachers, a subject of extreme importance for education in the context of cyberculture.

Keywords: Affectivity, Online Education, Research-training, Cyberculture.

\section{Introdução}

Comovo-me em excesso, por natureza e por ofício. Acho medonho alguém viver sem paixões (Ramos).

É com a célebre frase de Graciliano Ramos, em Memórias do Cárcere, que se justifica o tema escolhido para esta pesquisa, a afetividade na Educação Online. Do afeto como combustível para aprender e ensinar, que poderá vir a ser um elo necessário para manter acesa a chama da curiosidade, tão necessária no processo de ensino-aprendizagem na modalidade.

Inspirada no comportamento geracional nas redes sociais, em que pessoas do mundo inteiro interagem, se relacionam, trocam informações, criam intimidades e laços de afetividade sem nunca ter visto o seu interlocutor pessoalmente, busca-se transpor esse comportamento para os ambientes virtuais de aprendizagem (AVA), na percepção de que falta algo para que se estabeleça essa intimidade, esse vínculo entre educador e educando, produzindo interação, conhecimento do outro e intimidade.

O objetivo do presente artigo é apresentar a pesquisa sobre afetividade na Educação Online utilizando o método da pesquisa-formação na cibercultura no âmbito do curso de extensão Formação de Docentes para a Educação Online, do Instituto Federal de Educação, Ciência e Tecnologia do Rio de Janeiro (IFRJ). Surgiu a seguinte questão: quais condutas ou atividades contribuem para a construção de vínculos afetivos na educação online? 
Com a finalidade de responder tal questionamento, o dispositivo" de pesquisa "Síncrono ou Assíncrono? Eis a questão..." foi acionado no contexto da docência na educação online. Com base nas construções colaborativas, das interações no AVA e no Facebook da turma, dados emergiram, colaborando para o entendimento do objeto de pesquisa, concebendo a noção subsunçora² que será desenvolvida na relação entre as análises bibliográficas, o cotidiano da pesquisa e as narrativas emergentes.

O presente texto foi desenvolvido em tópicos específicos: na seção 1, esta introdução, apresentamos o tema da pesquisa, o método, o dispositivo e o objetivo principal do artigo; na seção 2, a conversa sobre afetividade e Educação Online; na seção 3, a demonstração do método pesquisa-formação na cibercultura; na seção 4, os achados da pesquisa pela noção subsunçora que emergiu do campo; e, na seção 5, algumas considerações conclusivas como síntese dos conteúdos abordados.

\section{Afetividade e Educação Online}

Ninguém educa ninguém, ninguém educa a si mesmo, os homens se educam entre si, mediatizados pelo mundo (Freire, 1987, p. 79).

Esta afirmativa revela o quanto esse grande educador estava à frente do seu tempo. Dita em um contexto histórico nacional em que havia um estado de exceção de direitos, ele ousou se referir à importância da liberdade, da autonomia, do diálogo, da troca, da interação com o meio, da importância da produção do conhecimento e do estímulo ao pensamento crítico em ambientes escolares. Mais que isso, quando conclui sua fala com a expressão "os homens se educam entre si, mediatizados pelo mundo", para além da crítica à "educação bancária", podemos interpretar como um prenúncio do que seria hoje a cibercultura ao considerar, naquele contexto, a importância da educação colaborativa, um processo educacional em rede, em que o saber de um não se sobrepõe ao saber do outro.

Afetividade é uma terminologia complexa e abrangente que está relacionada à vivência dos indivíduos em determinadas circunstâncias e às suas mais diversas formas de expressão. Seria, portanto, um termo genérico que potencializa o que é afetivo, o que dá significado ao conjunto de afetos que sentimos em relação à vida, às pessoas, às coisas, a nós mesmos em determinadas circunstâncias.

Como na Pedagogia Engajada, defendida por Hooks (2013), a afetividade que muitas vezes se estabelece na relação entre professor e aluno age como mais um aspecto motivador para a aprendizagem, pois proporciona um clima de confiança entre as partes, deixando os alunos à vontade para questionar e expressar suas dúvidas e anseios, vivências e experiências, aspectos que são essenciais para uma aprendizagem significativa, que por sua vez é aquela em que o processo educativo faz sentido para os aprendizes.

De acordo com as leituras referenciadas neste trabalho, podemos observar que só é possível estabelecer uma relação significativa de ensino-aprendizagem por meio de abordagens afetivas na educação online, pois, ainda que essa modalidade de ensino seja vista por muitos como uma ameaça aos afetos por conta do uso da máquina, trata-se de uma relação essencialmente humana. Precisamos nos apropriar da tecnologia da informação como mediadora da Educação, significada a partir dos usos humanos.

No decorrer desta pesquisa pudemos constatar diferentes concepções de afeto por autores e áreas do conhecimento diversos. No entanto, em um estudo mais recente, em que são considerados o corpo e a

1 Dispositivos são "meios materiais e/ou intelectuais, fazendo parte de uma estratégia de conhecimento de um objeto" (Ardoino, 2003, p. 80).

2 Noções subsunçoras são o esforço em interpretar o que emergiu do campo, o que se constrói e se aprende a partir da pesquisa; vem da empiria e da sua formação prévia. Uma noção que emerge da conversa com os dados, com a prática e com suas vivências. Pode-se considerar o achado da pesquisa. 
mente humana dentro da mesma perspectiva, Damásio (2000) afirma que as emoções usam o corpo para se representar. Assim sendo, considera que o afeto é a representação das emoções circunstanciadas, ou seja, amor, ódio, alegria, tristeza, enfim. Podemos deduzir que não há nenhuma conduta humana, por mais intelectual ou tecnológica que seja, que não passe por fatores afetivos. Concordo com Veiga (2007), quando diz que "não há relação possível, seja ela entre o homem e a máquina, o homem e a natureza, o homem e o texto, ou entre o homem e o homem que não seja relação afetiva". Já que é possível uma relação afetiva que perpassa o homem e a máquina, como podemos evidenciá-la na educação online?

A educação online é concebida para promover a (co)autoria do aprendente, a mobilização da aprendizagem crítica e colaborativa, a mediação docente voltada para interatividade e partilha, traz a cibercultura como inspiração e potencializadora das práticas pedagógicas, visa a autonomia e a criatividade na aprendizagem (Santos; Carvalho; Pimentel, 2016, p. 24).

A Educação Online não é definida exclusivamente pelas tecnologias digitais; também é amparada pela interatividade, afetividade, colaboração, coautoria, aprendizagem significativa, entre outros, buscando a visão de que aprendemos qualitativamente nas trocas e nas construções conjuntas. Estabelecendo comunidades de conhecimento mediadas pelo digital em rede, em espaços presenciais e no ciberespaço, a Educação Online assume paradigma que congrega a perspectiva comunicacional com a tecnológica e a pedagógica.

No esforço desta pesquisa, é possível perceber que a afetividade pode ser sentida nos ambientes virtuais na medida em que as ações de interatividade sejam mais constantes, em que o docente online atue como mediador do conhecimento, por meio de uma abordagem mais afetiva, ou seja, fazendo-se presente no ambiente virtual e atento à "movimentação" dos alunos; procurando atendê-los individual e atenciosamente; lendo e respondendo atentamente aos seus trabalhos; participando ativamente dos fóruns, buscando agregá-los e instigá-los ao novo, como também estimulando a interação de uns com os outros.

Essa afetividade não é materializada por escrever beijos e abraços ao final das mensagens, mas em um sentido mais amplo e comprometido como, por exemplo, ao se fazer presente e atenta à movimentação dos alunos no ambiente virtual; ao atender individualmente e atenciosamente cada aluno; ao responder às suas dúvidas rapidamente; ao ler atentamente os seus trabalhos e escrever pareceres comprometidos e críticos; ao participar ativamente dos fóruns buscando agregá-los e instigá-los a novas aprendizagens. Desse mesmo modo, exige comprometimento, responsabilidade, participação, pontualidade (Monteiro et al., 2014, p. 3.010).

Há que se atentar para o fato de que, nesse formato, é desejável que o docente online tenha habilidades e competências específicas para desempenhar o seu papel no AVA. No entanto, se não tiver suporte estrutural da instituição de ensino, poderá se sobrecarregar acumulando funções administrativas, técnicas e até mesmo de pedagogo, assumindo a função de orientação educacional, traçando o perfil de cada aluno, conhecendo sua realidade, características e possíveis dificuldades de aprendizagem; no caso da Educação Online, caberia até avaliar o nível de conhecimento tecnológico mínimo para um melhor desempenho.

A pesquisa foi desenvolvida diante de tal contexto, buscando reflexões constantes a respeito da afetividade na Educação Online. Adotamos a pesquisa-formação na Cibercultura como método para atingir o objetivo de compreender a relação de afetividade entre docentes e alunos nos ambientes virtuais de aprendizagem e seus contextos que envolvem tempo, tecnologia e distância. O método será o tema das próximas considerações. 


\section{Pesquisa-formação na cibercultura}

Partindo do pressuposto de que investigador e investigado são praticantes ${ }^{3}$ em interação e potenciais pesquisadores, tem-se como método a pesquisa-formação na cibercultura (Santos, 2014), formação como processo coletivo e pesquisa como rompimento das formas tradicionais ou quantitativas de pesquisar, questionando o paradigma moderno de fazer ciência. É uma pesquisa na cibercultura, pois aciona ambiências tecnológicas e dispositivos de pesquisa no contexto da Educação Online.

Tendo em vista a prática docente online inerente ao método, há a elaboração do desenho didático, considerado um planejamento, desde o diagnóstico à avaliação, uma idealização dos conteúdos para a disciplina online, o percurso didático e metodológico idealizado pelo docente imerso na cultura contemporânea mediada pelo digital em rede, na relação entre a cidade e o ciberespaço.

Santos, Carvalho e Pimentel (2016) afirmam que a pesquisa-formação é um método de pesquisa em que o docente-pesquisador pesquisa a sua prática, não separando o ato educativo do ato de pesquisar, em contexto de cibercultura, na Educação Online. Ou seja, a pesquisa-formação na cibercultura nos dá a possibilidade de interagir, criar, produzir, formar e informar em rede, tendo alternância de papel como formador-pesquisador sem que um anule o outro, além de reconhecer a importância do aprendente que, nesse processo, acaba sendo o protagonista.

A experiência foi realizada no curso de extensão Formação de Docentes para a Educação Online, do Instituto Federal de Educação, Ciência e Tecnologia do Rio de Janeiro (IFRJ), campus Belford Roxo, no primeiro semestre de 2017. O curso foi oferecido na modalidade semipresencial, de 23 de maio a 27 de junho de 2017, para uma turma de 23 praticantes com perfil bastante heterogêneo, com média a partir de 30 anos, de várias áreas de formação e atuações profissionais, em geral graduados, buscando uma nova formação para aumentar os índices de empregabilidade.

No decorrer desta pesquisa pudemos constatar a importância da afetividade para um melhor desenvolvimento no processo de ensino-aprendizagem. Nos espaços físicos a construção do vínculo afetivo se dá por uma série de abordagens em que o docente procura conhecer melhor as peculiaridades do aluno observando o seu comportamento e linguagens verbais ou não; na Educação Online não é diferente. No entanto, a construção desse vínculo em ambientes online pode se dar por meio da comunicação verbal e escrita, por exemplo, ou via tecnologias que sejam capazes de representar as emoções e sentimentos.

Como o método selecionado não está apartado da docência online, um planejamento pedagógico é realizado em forma de desenho didático ou dispositivo de pesquisa, que se complementam na estrutura curricular do curso. O dispositivo é acionado considerando a questão norteadora e os objetivos da pesquisa; dele emergem narrativas ${ }^{4}$ e experiências compartilhadas com os praticantes ciberculturais. A pesquisa acontece no desenvolvimento desses processos educativos, buscando a compreensão de fenômenos diversos; neste caso, a afetividade na Educação Online. A seguir apresentaremos os usos feitos para construir o achado da pesquisa, que é a noção subsunçora "Atividades síncronas: pertencimento e afetividade".

\section{Atividades síncronas: pertencimento e afetividade}

Damásio (2000) afirma que considera o corpo e a mente dentro de uma mesma perspectiva para entender as representações de afetividade; podemos considerar que em um ambiente virtual de aprendizagem essa manifestação pode ser representada pela comunicação textual, imagética e audiovisual, por

3 “Termo de Certeau (1994) para aquele que vive as práticas/táticas cotidianas" (Alves, 2008, p. 10).

4 A partir das inspirações nos estudos nos/dos/com os cotidianos (Alves, 2008), consideramos as narrativas dos praticantes e as experiências originárias do mergulho no campo de pesquisa como equivalentes às análises bibliográficas. 
exemplo, sendo amplamente explorada ao longo do curso, de forma a proporcionar uma multiplicidade de formatos, privilegiando as preferências de aprendizagem dos alunos.

O desenho didático do curso foi estruturado considerando os módulos Ambientação, Fundamentos da Cibercultura, Educação Online, Mídias Sociais na Educação, Tecnologias Educacionais, Recursos Multimídia e Educação e Mediação Pedagógica Online, com encontros presenciais e online, síncronos ou assíncronos. Desenhamos o curso com a finalidade de mobilizar saberes sobre a docência online para a interatividade, colaboração e afetividade. As atividades propostas possuíam como objetivo a vivência dos praticantes como docentes online, de forma a valorizar a modalidade e as possíveis construções colaborativas que poderiam acontecer.

Ao longo do curso desenvolvemos duas atividades síncronas: chat e videoconferência; e quatro atividades assíncronas 5 : fórum, debate no Facebook, diário de bordo e atividade colaborativa no Google Docs. É importante destacar que as avaliações foram amparadas pelas atividades assíncronas, para garantir a participação dos praticantes. As atividades síncronas foram utilizadas como bônus para aqueles que estavam com atividades pendentes, de forma a não prejudicar quem não conseguisse estar presente sincronamente, sem deixar de oportunizar a experiência em atividades tão enriquecedoras.

Concordando com Santos, Carvalho e Pimentel (2016), que afirmam que o fórum de discussão, junto com o e-mail e o bate-papo, são os meios de conversação mais utilizados nos ambientes virtuais de aprendizagem, acionamos o dispositivo de pesquisa "Síncrono ou assíncrono? Eis a questão..." utilizando um fórum de discussão para que mais dados sobre a afetividade pudessem emergir. Pedimos aos praticantes da pesquisa que respondessem: como as atividades síncronas e assíncronas os afetaram ao longo do curso? Dessa forma, subsídios para responder às questões da presente pesquisa viriam à tona. O dispositivo está ilustrado na Figura 1.

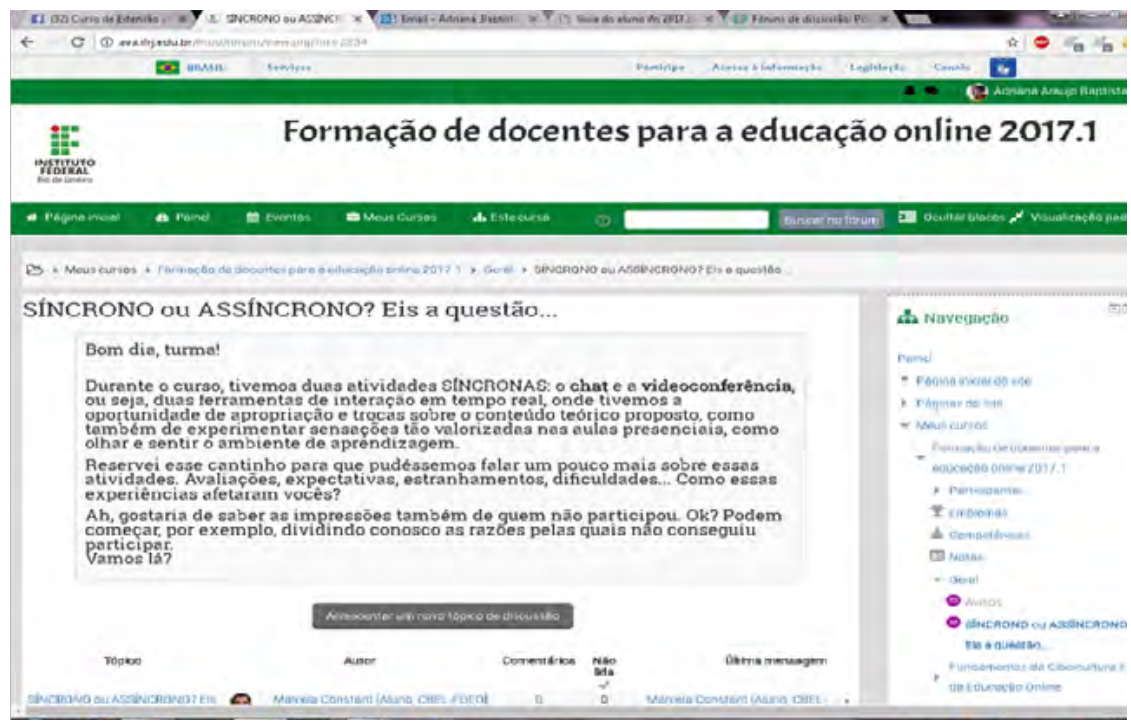

Figura 1: Captura de tela do dispositivo de pesquisa no ambiente virtual de aprendizagem Moodle.

Essa atividade contou com a participação de 14 praticantes, ocasião em que todos se dirigiram somente ao professor e não interagiram entre si, exemplificando o que Pimentel (2015, apud Santos; Carvalho; Pimentel, 2016, p. 23) problematiza, de que a interação nos meios de conversação online, quando usados no contexto educacional, nem sempre promove a interatividade e a colaboração. Entretanto, o papel da afetividade na Educação Online, objeto de estudo desta pesquisa, pôde ser analisado e representado em diferentes depoimentos que mostraremos a seguir.

5 As atividades síncronas acontecem ao mesmo tempo, enquanto as atividades assíncronas acontecem em momentos diferentes. 


\section{Síncrono ou assíncrono? Eis a questão... \\ por Andréa Xavier Alexandre [Aluno_CBEL-FDEO] - quinta, 22 Jun 2017, 10:50}

No decorrer do curso, nas duas atividades que foram síncronas, ou seja, de interação com a participação em tempo real (sintonizados) do grupo em curso e professora e interlocutores, eu não consegui participar da forma que eu esperava. A expectativa é sempre de que vai dar tudo certo. $\mathrm{E}$ infelizmente não acontecia como esperado! Faz parte!

O fato de estar com um recurso digital (computador, netbook, tablet, celular, Android ou Ipod e Ipad) não me habilita ainda a afirmar que sei usar aproveitando tudo que esses recursos com a aparente impressão de infinitas possibilidades no fazer digital e online.

Percebo que preciso praticar mais, me sinto mais ambientada em atividades assíncronas, pois dessa forma é possível conciliar a disponibilidade pessoal, local e temporal e realizar com mais segurança. Porém, não dá para ficar só nessa prática, pois as atividades síncronas tornam o contato mais dinâmico e afetuoso, presente e participativo com mais percepção de pertencimento ao que está sendo discutido, apresentado, orientado, compartilhado e solidarizado ao momento de construção e participação coletiva.

As atividades do curso síncronas foram instigantes e desafiadoras, conseguindo ou não o fato de tentar, já me faz perceber que é preciso tentar mais vezes e que é possível. Só não estou ainda familiarizada com essa atividade. Pois há algumas interfaces que, não sendo dominadas, e alguns comandos necessários desconhecidos torna-se difícil. Conseguir estarmos juntos em um mesmo tempo não é algo simples, requer planejamento e até um sacrifício, pois às vezes seria o tempo de estar em alguma atividade de rotina, mas que em um dado momento poderia ser dispensada ou conformidade com a atividade síncrona tipo chat.

A minha dificuldade em saber mesmo acessar e conseguir usar a ferramenta. Gostaria de sugerir que em atividades como essas, fosse possível no curso haver uma oficina presencial no laboratório com cada qual usando os seus dispositivos e até mesmo com computadores e sob a orientação do instrutor/professor, em ajudar a chegar aos ajustes e acertos do que foi anteriormente uma experiência negativa (atividade anterior síncrona proposta) de falha, com várias dúvidas e perguntas sobre o que impediu de conseguir participar. Nesse caso, reporto a mim mesma.

Essas atividades me afetaram, sim! mas de modo a perceber e entender que preciso ensaiar mais e sem medo de fazer, participar, arriscar e assim, eu acredito que tão logo consiga aprimorar o uso das tecnologias com atividades síncronas que foram meu desafio mais pertinentes neste curso.

Avalio como atividades síncronas necessárias atualmente e que cada vez mais se faz necessária e atrativa no campo de ensino-aprendizagem e até mesmo no campo profissional para as exigências e expectativas do mercado de trabalho. Quando o acesso é de participação se consolida, acredito que o sentimento de pertencimento à atividade e de colaboração afeta mais positivamente, porém quando não conseguimos nos conectar de modo combinado síncrono, gera sim!, uma sensação de frustração e de incapacidade momentânea sem respostas com a tal "sensação" de que estamos sós (enquanto o mundo está conectado no chat ou na videoconferência e você não!). Na fala de alguns com uma experiência e maturidade é possível saber se superar e decidir avançar em busca de aprender até conseguir dominar, para outros, ouvir a desistência é saltar de si, é preciso lembrar que aprender algo é ensaio e erro(s) até o acerto(s). Uma hora acontece e quando acontecer, lembrar que continuamos em avançar para mais aprender e saber, pois tudo muda, avança e transforma progressivamente. Aqui deixo minha colaboração, Andréa Xavier Alexandre.

O depoimento da praticante Andréa foi reproduzido na íntegra devido ao tamanho da sua contribuição para esta pesquisa em todos os aspectos. Ela faz uma análise da sua imersão no formato da Educação Online, ressaltando o que a afetou nessa caminhada. Seu depoimento nos arrebata, carregando de sentidos o fazer do educador e emergindo a noção subsunçora "Atividades síncronas: pertencimento e afetividade".

A palavra pertencimento foi destacada na narrativa de Andréa: "as atividades síncronas tornam o contato mais dinâmico e afetuoso, presente e participativo com mais percepção de pertencimento ao que 
está sendo discutido, apresentado, orientado, compartilhado e solidarizado ao momento de construção e participação coletiva".

\begin{abstract}
Pertencimento ou o sentimento de pertencimento é a crença subjetiva numa origem comum que une distintos indivíduos. Os indivíduos pensam em si mesmos como membros de uma coletividade na qual símbolos expressam valores, medos e aspirações. Esse sentimento pode fazer destacar características culturais e raciais (Dicionário Informal ${ }^{6}$, 2017).
\end{abstract}

Ao estimular a ajuda mútua, a construção coletiva dos conhecimentos, a realização de trabalhos em conjunto em atividades síncronas e outras ambiências coletivas, buscamos diminuir a sensação de solidão que acomete alguns alunos de cursos a distância. Como a definição da palavra já orienta, é a sensação dos praticantes como membros de uma coletividade, fazendo parte de um grupo, uma cultura. Fabiana também demonstrou a sensação de pertencimento estimulada pela atividade síncrona.

\title{
Síncrono ou assíncrono \\ por Fabiana Souza de Oliveira [Aluno_CBEL-FDEO] - domingo, 25 Jun 2017, 21:19
}

Gosto muito das atividades síncronas, pois acredito que essas atividades fortalecem uma afetividade e interação entre os membros. Essa interação é muito importante na modalidade de ensino online. Por outro lado, as atividades assíncronas são necessárias no curso. E o aluno precisa entender que existe a necessidade de concluí-las. Tive dificuldades na videoconferência, pois a internet ficava caindo e não consegui acompanhar a explicação da professora para realizar a atividade da semana. Mas o pouco tempo que consegui ficar na videoconferência foi muito bom, a sensação foi de pertencimento e é bom sentir essa ligação.

A construção de um ambiente virtual de aprendizagem precisa privilegiar o sentimento de pertencimento necessário a um contexto cooperativo e colaborativo e deve privilegiar um efetivo conhecimento das pessoas que resulte em desenvolvimento de afinidades, o que atenuará dificuldades inerentes à aprendizagem na modalidade a distância (Sihler; Ferreira, 2011, p. 4).

As autoras ressaltam as relações interpessoais como fator que atenua as dificuldades na sensação de distância. Destacamos o diálogo entre as praticantes Lívia e Andréa, evidenciado o vínculo afetivo que pode acontecer em cursos online. As praticantes realizaram trabalho em grupo juntas e, com base nisso, foi possível observar a troca de afetos que poderá se estender para além do ambiente virtual de aprendizagem.

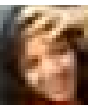

\section{$\underline{\text { Lívia Vilar }}$}

A comunicação no AVA e Facebook foi de grande importância, pois um complementava o outro e nos ajudava a ter mais informações e não esquecer de realizar as atividades, além de trazer união com a participação da turma, assim o curso não ficou monótono, pois um tirava a dúvida do outro. Agora também concordo que o tempo foi curto.

6 Disponível em: http://www.dicionarioinformal.com.br/pertencimento/. Acesso em: 28 jul. 2017. 
⿶9

Lívia Vilar

Andréa, vc pode me visitar lá na Praia Vermelha.

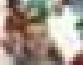

\section{Andréa Xavier Alexandre}

Sim... Terá em agosto um curso que irei fazer no IBC lá pertinho e te falo... aí nos encontramos por lá... dia 2 de agosto até 4 setembro sempre às segundas e quartas... bjs! Até lá!

Afetividade é uma terminologia complexa e abrangente que está relacionada à vivência dos indivíduos em determinadas circunstâncias e às suas mais diversas formas de expressão. É possível identificar tal sentimento nas narrativas das praticantes. O afeto como combustível para aprender e ensinar, que poderá vir a ser um elo necessário para manter acesa a chama da curiosidade, tão necessária no processo de ensino-aprendizagem na modalidade de Educação Online.

Nos achados desta pesquisa procuramos responder sobre o papel da afetividade na educação e, principalmente, sobre a sua importância na Educação Online. A noção subsunçora "Atividades síncronas: pertencimento e afetividade" emergiu do campo, em que observamos no chat e na videoconferência maior aproximação, seja quando os praticantes se ajudavam para conseguir acesso ou quando dialogavam ao longo da atividade. Essas experiências nos alertaram para a potencialidade de tais atividades e instigaram a criação do dispositivo de pesquisa, que contribuiu significativamente para nossas percepções sobre Educação Online.

Foi possível perceber que a afetividade é identificada por meio da ação diligente do docente online, em ações síncronas ou assíncronas, tendo maior representatividade nas ações em tempo real, ou seja, nas atividades síncronas. Quanto aos depoimentos, percebe-se na própria espontaneidade das afirmativas, um sentimento de valorização e autoestima elevada. Os vínculos afetivos se construíram com base na confiança postulada ao docente, cuja conduta generosa, sempre presente, e comunicação leve e instigante deram ao curso uma enorme sensação de mobilidade, de aconchego e acolhimento.

\section{Considerações Finais}

Considerando que o ato de educar pressupõe uma construção conjunta entre educador e aprendente e que só é possível estabelecer uma relação de ensino-aprendizagem mediada por uma abordagem afetiva, podemos concluir que, a exemplo dos ambientes escolares presenciais, é possível construir uma relação afetuosa calcada na produção do conhecimento, do pensamento crítico e autônomo nos ambientes virtuais de aprendizagem e estabelecer vínculos afetivos entre esses pares, ainda que educadores jamais tenham se visto, ainda que separados no espaçotempo, ainda que separados pela tela do computador, já que a educação é uma atividade essencialmente humana.

A afetividade na Educação Online pode ser percebida em comunicação audiovisual, como nas videoconferências; comunicação imagética, como os emojis e memes do Facebook ou pela comunicação textual, exemplificada nesta pesquisa como uma das formas de representação das emoções do sujeito.

Os dados que emergiram foram evidenciados nas narrativas dos praticantes no diálogo na rede social Facebook e no fórum Síncrono ou assíncrono? Eis a questão..., dando conta de que a afetividade é pos- 
sível na Educação Online. No entanto, há que se ressaltar que as práticas do docente online constatam a ressignificação do papel do professor no AVA, para que a abordagem afetiva trouxesse resultados reais, considerando a interatividade, a disponibilidade e a coautoria.

Podemos concluir que a afetividade, para além das falas dos praticantes da pesquisa, pôde ser sentida também no fazer cotidiano da educadora ao realizar ações diligentes de interação, se fazendo presente no AVA e instigando a colaboração mútua, que são fatores determinantes para o sucesso dessa modalidade de ensino. $\mathrm{O}$ achado da pesquisa propicia saberes para o desenvolvimento de cursos online, proporcionando uma educação de qualidade, contextualizada com a cultura contemporânea e com os sujeitos ciberculturais.

\section{Referências Bibliográficas}

Alves, Nilda (2008). Decifrando o pergaminho: o cotidiano das escolas nas lógicas das redes cotidianas. In Inês Barbosa Oliveira; Nilda Alves (orgs.). Pesquisa nos/dos/com os cotidianos das escolas. $3^{\text {a }}$ ed. Rio de Janeiro: DP\&A, p. 13-38.

Ardoino, J. (2003). Para uma pedagogia socialista. Brasília: Plano.

Damásio, A. (2000). O mistério da consciência: do corpo e das emoções ao conhecimento de si (2ª reimpr.). São Paulo: Companhia das Letras.

Freire, P. (1987). Pedagogia do Oprimido. $17^{\mathrm{a}}$ ed. Rio de Janeiro: Paz e Terra.

Hooks, B. (2013). Ensinando a transgredir: a Educação como prática de liberdade. Trad. Marcelo Brandão Cipolla. São Paulo: Martins Fontes.

Monteiro, A. F. et al. (2014). A afetividade na relação tutor-aluno: o ensinar e o aprender na educação online. In XI Congresso Brasileiro de Ensino Superior a Distância (ESUD). Florianópolis, SC. Disponível em: http:// esud2014.nute.ufsc.br/anais-esud2014/files/pdf/128134.pdf

Santos, E. O. (2014). Pesquisa-formação na cibercultura. Santo Tirso: Whitebooks.

Santos, E. O.; Carvalho, F. S. P.; Pimentel, M. (2016). Mediação docente online para colaboração: notas de uma pesquisa-formação na cibercultura. ETD - Educação Temática Digital, 18, n. 1, 23-42. Disponível em: https://periodicos.sbu.unicamp.br/ojs/index.php/etd/index.

Sihler, A. P.; Ferreira, S. M. B. (2011). A afetividade mediada por meio da interação na modalidade a distância como fator preponderante para a diminuição da evasão. $17^{\circ}$ Congresso Internacional ABED de Educação a Distância (17 CIAED). Manaus, AM. Disponível em: http://www.abed.org.br/congresso2011/cd/116.pdf.

Veiga, A. L. S. (2007). Relação e emoção na educação a distância - o afeto possível. Revista Ramal de Ideias. Disponível em: http://www.ufac.br/site/unidades-administrativas/orgaos-complementares/edufac/ revistas-eletronicas/revista-ramal-de-ideias/edicoes/edicao-1/caminhos-da-educacao/relacao-e-emocao-na-educacao-a-distancia/at_download/file. 